\title{
PERIODONTITE AGRESSIVA: REVISÃO DE LITERATURA
}

\author{
Renata de Araújo Barbosa Mestranda e especialista em Periodontia pela \\ Associação Brasileira de dontologia - Seção \\ Bahia. \\ Sandro Bittencourt Souza Doutor em Clínica Odontológica, área de \\ Periodontia, pela Faculdade de Odontologia de \\ Piracicaba da Universidade de Campinas. \\ Professor Adjunto da Escola Bahiana de \\ Medicina e Saúde Pública. \\ Érica Del Peloso Ribeiro Doutor em Clínica Odontológica, área de \\ Periodontia, pela Faculdade de Odontologia de \\ Piracicaba da Universidade de Campinas. \\ Professor Adjunto da Escola Bahiana de \\ Medicina e Saúde Pública.
}

\begin{abstract}
Resumo
A periodontite agressiva (PAg) acomete indivíduos clinicamente saudáveis, exceto pela presença da doença periodontal, caracterizando-se por rápida perda de inserção e destruição óssea e ainda pela agregação familiar, dentre outras características secundárias. A rápida destruição periodontal presente na PAg é um fator de extrema importância e desperta a atenção de pesquisadores em todo o mundo, uma vez que se deparam com uma infecção caracterizada por uma microbiota altamente virulenta e/ou um alto nível de susceptibilidade do indivíduo. O risco de perdas dentárias e comprometimento da função e estética, principalmente em pacientes jovens, mais comumente acometidos pela PAg, também estimulam a busca por respostas e tratamentos mais eficientes no controle da doença. Diante disso, o objetivo deste trabalho foi realizar uma revisão de literatura sobre a periodontite agressiva abordando as descobertas sobre a etiologia microbiana e susceptibilidade do indivíduo, assim como sua resposta às diferentes abordagens terapêuticas.
\end{abstract}

Palavras-chave: Periodontite agressiva; Susceptibilidade; Microbiologia; Tratamento.

\section{AGGRESSIVE PERIODONTITIS: A LITERATURE REVIEW}

\begin{abstract}
The aggressive periodontitis ( $\mathrm{AgP})$ occurs on clinically health individuals, except for the presence of periodontal disease, is characterized by rapid attachment loss and bone destruction and also by family aggregation, among other secondary characteristics. The rapid periodontal destruction observed in $\mathrm{AgP}$ is an extremely important factor and have raised the researchers attention all over the world, once one come across an infection characterized by a highly virulent microorganism and/or by highly susceptible individuals. The risk of tooth loss and function and esthetic compromising, mainly in young patients, more commonly affected by the AgP, also stimulates the search for answers and more efficient treatments in the disease control. Therefore, the aim of this study is to review the literature of aggressive periodontitis considering the findings in the microbial etiology and individual susceptibility, as well as its response to periodontal therapy and the search for alternatives that lead to benefits in the periodontal clinical parameters.
\end{abstract}

Keywords: Aggressive periodontitis; Susceptibility; Microbiology; Treatment. 


\section{INTRODUÇÃO}

O fator etiológico primário da doença periodontal é o biofilme dental que atua por meio de mecanismos diretos, causando destruição tecidual pela liberação de enzimas líticas e produtos citotóxicos, e indiretos, desencadeando as reações de defesa do hospedeiro que podem resultar em destruição progressiva do periodonto. ${ }^{(1)}$

A periodontite é uma infecção que pode se manifestar com apresentações clínicas diferentes e hoje várias linhas de evidências sustentam a existência de formas verdadeiramente diferentes de periodontite. ${ }^{(2)}$ A Classificação das Condições e Doenças Periodontais, desenvolvida em 1999, no Workshop Internacional, ${ }^{(3)}$ utilizada atualmente, reclassificou as formas de periodontite em três tipos diferentes (crônica, agressiva e necrosante) e em manifestações periodontais de doenças sistêmicas. ${ }^{(3)}$

A periodontite agressiva acomete indivíduos clinicamente saudáveis, exceto pela presença da doença periodontal, caracteriza-se pela rápida perda de inserção e destruição óssea e ainda pela agregação familiar. ${ }^{(3)}$

A rápida destruição periodontal presente na PAg é um fator de extrema importância e desperta a atenção de pesquisadores em todo o mundo, uma vez que se deparam com uma infecção caracterizada por uma microbiota altamente virulenta e/ou um alto nível de susceptibilidade do indivíduo. ${ }^{(4)} \mathrm{O}$ risco de perdas dentárias e comprometimento da função e estética, principalmente em pacientes jovens, mais comumente acometidos pela PAg, também estimulam a busca por respostas e tratamentos mais eficientes na remissão da doença.

Diante disso, este trabalho tem por objetivo realizar uma revisão de literatura sobre a periodontite agressiva abordando as descobertas sobre a etiologia microbiana e susceptibilidade do indivíduo, assim como sua resposta às diferentes abordagens terapêuticas.

\section{REVISÃO DE LITERATURA}

\section{Conceito e Características}

O termo "periodontite agressiva" foi criado em 1999, visando à substituição de termos como periodontite de acometimento precoce ou periodontite juvenil e assim descartando a terminologia baseada na idade do indivíduo ou que requeresse conhecimento sobre o índice de progressão da doença. ${ }^{(3)}$ 
Dentre as doenças periodontais, a PAg é uma infecção rara, frequentemente grave, podendo se apresentar em qualquer grupo étnico e idade, no entanto, é muitas vezes caracterizada pela idade precoce da manifestação clínica. ${ }^{(5)}$ Pode ser classificada em localizada, com início na puberdade, resposta intensa dos anticorpos aos agentes infecciosos, com perdas ósseas proximais localizadas em primeiros molares e incisivos e envolvendo não mais que dois dentes além destes; e generalizada, afetando usualmente pessoas abaixo dos 30 anos, no entanto pode se apresentar em pacientes mais velhos, pobre resposta dos anticorpos aos agentes infecciosos, natureza episódica pronunciada da perda de inserção e osso alveolar, com perda de inserção interproximal generalizada, afetando ao menos três dentes permanentes além dos primeiros molares e incisivos. ${ }^{(1)}$

Algumas características secundárias também têm sido relatadas, como: quantidade de biofilme inconsistente com a severidade da destruição do tecido periodontal, elevadas proporções de Agregatibacter actinomycetemcomitans (Aa) e, em algumas populações, Porphyromonas gingivalis (Pg), anormalidades fagocitárias, fenótipo de macrófagos hiperresponsivos incluindo índices elevados de prostaglandina E2 (PGE2) e interleucina 1-beta $(\mathrm{IL}-1 \beta){ }^{(1)}$

\section{Epidemiologia}

Poucos dados existem sobre a prevalência e distribuição da PAg na população em geral. No entanto, entre os indivíduos caucasianos, a doença parece afetar as mulheres com maior frequência que homens e sua prevalência de maneira geral é baixa $(\approx 0,1 \%) .{ }^{(6)}$ Entre outras raças, e em particular em indivíduos negros, a prevalência da doença é maior (até $2,6 \%)^{(7)}$ e a razão entre os sexos parece ser inversa, uma vez que os homens são mais frequentemente afetados. ${ }^{(6)}$ A prevalência em espanhóis, caucasianos e afro-americanos pode variar entre $0,1 \%$ e $15 \%{ }^{\left({ }^{(}\right)}$

Ao examinar na literatura a prevalência da PAg em estudos de agregação familiar, pode-se observar uma porcentagem de familiares afetados variando entre $8 \%$ num grupo de famílias no Reino Unido ${ }^{(9)}$ até $63 \%$ numa família brasileira. ${ }^{(10)}$

Apenas um estudo realizado nos Estados Unidos da América ${ }^{(11)}$ relata a prevalência das formas localizada e generalizada da doença periodontal de acometimento precoce, nomenclatura utilizada na época para PAg. Os autores relatam um diagnóstico quatro vezes 
mais frequente da forma localizada em relação à generalizada, tanto em brancos quanto em negros.

\section{Periodontopatógenos}

O Simpósio Mundial de Periodontia, em $1996^{(12)}$ designou as espécies Aa, Pg e Tannerella forsythia (Tf) como patógenos periodontais. O Aa tem recebido atenção particular e é considerado um microrganismo chave na agressiva periodontite localizada (PAgL). ${ }^{(2,13,14)}$ A classificação de 1999 também cita Pg como agente etiológico da PAg, no entanto, seu papel permanece ainda questionável. ${ }^{(15)}$

A rápida progressão da doença e a possibilidade de estar relacionada com microrganismos altamente virulentos despertaram a busca por características bacterianas que pudessem ser responsáveis pela maior destruição periodontal. Nesse sentido, tem-se buscado a detecção de diferentes cepas do Aa e seus fatores de virulência como leucotoxina, lipopolissacarídeos (LPS), bacteriocinas e secreção de vesículas membranosas. ${ }^{(2)} \mathrm{O}$ Aa é ainda capaz de invadir os tecidos moles ${ }^{(16)} \mathrm{e}$, portanto, capaz de recolonizar a bolsa periodontal após a raspagem e alisamento radicular. ${ }^{(17)} \mathrm{Pg}$ também tem sido descrita como uma bactéria capaz de penetrar nos tecidos gengivais. ${ }^{(18)}$

Uma pesquisa sobre a prevalência de periodontopatógenos em brasileiros avaliou 203 indivíduos, 178 com periodontite crônica e 25 com PAg, ${ }^{(19)}$ e detectou que os pacientes com PAg apresentavam índice de placa significativamente menor, profundidade de sondagem significativamente maior, maior prevalência de Aa, Aa altamente leucotóxico e Campylobacter retus (Cr) e igual prevalência de Pg para ambas as doenças. Outros microrganismos como Prevotella intermedia (Pi) e Tf também foram avaliados, no entanto, nenhuma diferença estatística entre os grupos foi encontrada. Observou-se também que os pacientes portadores do Aa altamente leucotóxico apresentavam maior perda de inserção clínica que os portadores de Aa minimamente leucotóxico e os não infectados por Aa. Dessa maneira, concluem que testes microbiológicos laboratoriais para a detecção do Aa altamente leucotóxico em crianças ou adolescentes afro-descendentes, pode prevenir a PAg.

$\mathrm{Na}$ Europa e nos Estados Unidos uma proporção relativamente pequena de Pg foi isolada nos estágios iniciais de periodontite agressiva, entretanto, essa bactéria tem sido identificada em pacientes no Chile e Jamaica. ${ }^{(20)}$ Outro trabalho ${ }^{(15)}$ relata que a maioria dos pacientes japoneses com PAg parecem estar mais infectados por Pg que por Aa. 
Diante da não obrigatoriedade da presença do Aa e Pg na patogênese da periodontite agressiva no Simpósio Mundial, em 1999, ${ }^{(1)}$ foi considerado que a presença em particular do Aa e Pg representa uma característica secundária da PAg.

Uma revisão de literatura a respeito dos determinantes da susceptibilidade do hospedeiro na PAg, ${ }^{(8)}$ têm demonstrado uma associação entre o herpes vírus, especialmente o vírus Epstein-Barr, o citomegalovírus humano e o vírus herpes simplex com PAg, e que os últimos parecem ser bons preditores para a presença subgengival de Pg em sítios com doença periodontal.

\section{Susceptibilidade do hospedeiro}

Em se tratando da susceptibilidade do paciente acometido pela PAg, não se pode falar isoladamente sobre os aspectos imunológicos e genéticos envolvidos na sua etiopatogenia. Esses aspectos se misturam numa cascata complexa de reações e respostas do organismo ao agente infeccioso, estando os fatores imunológicos submissos à coordenação da carga genética do indivíduo.

No sistema imune celular e humoral, diversas moléculas e células participam ativamente do processo de defesa e diferenças na população de células podem estar associadas a inúmeros fatores incluindo: herança genética do indivíduo, a presença ou ausência de um microrganismo específico, a severidade da agressão inicial, a duração e a severidade da doença. ${ }^{(21)}$

Estudos têm demonstrado que o fluido crevicular e o tecido periodontal de sítios inflamados são ricos em imunoglobulinas e citocinas inflamatórias. ${ }^{(22,23)}$ Ocorrem também alterações nos níveis de imunoglobulinas e citocinas no sangue periférico, aspecto que tem sido avaliado na tentativa de encontrar características que possam diferenciar os portadores da PAg dos indivíduos saudáveis ${ }^{(24,26)}$ e auxiliar no diagnóstico precoce da doença.

A interleucina-1 (IL-1) e o fator de necrose tumoral- alfa (TNF- $\alpha$ ) são as citocinas mais estudadas ${ }^{(25,26)}$ e com fortes evidências sobre o seu papel na destruição do periodonto. No entanto, os níveis de outras citocinas como IL-2, IL-4, IL-5, IL-10 e interferon-gama (IFN- $\gamma$ ), também têm sido avaliados. ${ }^{(22)}$

Sugere-se ${ }^{(22)}$ que uma quebra na homeostasia do sistema imune acarreta um desequilíbrio das citocinas, com redução da função anti-inflamatória, e desenvolvimento da PAg. 
Um estudo ${ }^{(27)}$ foi realizado a partir da análise de espécimes obtidos de regiões submetidas à exodontia ou aumento de coroa clínica, na tentativa de oferecer mais evidências sobre o papel dos neutrófilos polimorfonucleares (PMN) na patogênese da periodontite crônica e agressiva generalizada. Foram analisados espécimes de 10 indivíduos para cada grupo de periodontite e cinco saudáveis. Os autores concluíram que os sítios inflamados, tanto na periodontite crônica quanto na agressiva, apresentavam infiltração de grande quantidade de células inflamatórias, muitos PMN e seus mediadores no epitélio e conjuntivo subjacente, principalmente IL1- $\beta$ e TNF- $\alpha$, destruição severa do tecido conjuntivo e ulceração severa do epitélio.

Vale ressaltar que além do número elevado de PMN, diversas disfunções neutrofílicas têm sido reportadas na PAg incluindo anormalidades na adesão, quimiotaxia, geração de superóxidos, fagocitose e atividade bactericida. $^{(8)}$ A disfunção neutrofílica mais completamente descrita na periodontite agressiva é a quimiotaxia. ${ }^{(8)}$

Um grupo de pesquisadores ${ }^{(24)}$ avaliou os níveis plasmáticos das imunoglobulinas $\operatorname{IgG}$ e seus subtipos (IgG1, IgG2, IgG3 e IgG4), IgA e IgM, em caucasianos europeus, com doença periodontal crônica e agressiva, relacionando-as com severidade da doença, fumo, diagnóstico e prevalência dos periodontopatógenos Aa e Pg. Os autores se basearam na hipótese de que a não elevação dos níveis das imunoglobulinas poderia resultar em menor defesa do hospedeiro e aumento na severidade da doença. Foram avaliados 62 pacientes com doença periodontal crônica e 18 com PAg, fumantes e não fumantes. Concluíram que os indivíduos não apresentam diferenças nos níveis de IgG, IgA e IgM. Houve elevação apenas nos níveis de IgG1 e IgG2 em não fumantes com doença periodontal, com níveis maiores na medida em que aumenta a severidade, independente de serem infectados por $\mathrm{Aa}$ e $\mathrm{Pg}$ e de serem portadores de periodontite agressiva ou crônica.

É evidente que uma resposta específica dos anticorpos de suficiente magnitude, especificidade e avidez exerce um papel de proteção do periodonto, ${ }^{(21)}$ no entanto, não se conhece completamente a função da resposta imune humoral. ${ }^{(21,28)}$ Acredita-se que essa resposta no periodonto seja produzida tanto localmente quanto sistemicamente, sendo esta mais proeminente, atingindo os tecidos através do fluido crevicular. ${ }^{(29,30)}$

A detecção de níveis elevados de determinadas citocinas e anticorpos em pacientes com PAg, assim como a percepção do padrão de agregação familiar da doença, têm conduzido a realização de estudos ${ }^{(8,13,31,32,33)}$ com o objetivo de avaliar polimorfismos 
genéticos que possam estar associados com a maior ou menor produção de citocinas e anticorpos importantes na patogênese da doença, e a hereditariedade dos genes polimórficos.

Os resultados da análise de segregação não são ainda um consenso quanto a forma de herança genética. ${ }^{(8)}$ Inúmeros polimorfismos genéticos têm sido investigados como possíveis marcadores da maior susceptibilidade a PAg como os polimorfismos do gene para a produção da IL-1, IL-4, IL-10, TNF- $\alpha$, receptor Fc-gama, complexo principal de histocompatibilidade (MHC) e receptor de vitamina D. ${ }^{(8)}$

Uma revisão sistemática e meta-análise publicada em $2008^{(31)}$ avaliou seis polimorfismos para os genes de IL-1, IL-6 e TNF com o objetivo de investigar uma potencial associação entre determinado polimorfismo e a periodontite agressiva ou crônica. O estudo concluiu que nenhum dos polimorfismos testados demonstra uma associação significativa com a PAg.

$\mathrm{O}$ reconhecimento dos antígenos e sua apresentação às células $\mathrm{T}$ são cruciais para a resposta imune antígeno-específica eficiente contra o periodontopatógeno. ${ }^{(32)}$ A apresentação do antígeno e ativação das células T é realizada pelo MHC. Desta maneira, uma meta-análise, baseada em estudos de caso-controle, realizada em $2008,{ }^{(32)}$ buscou avaliar a associação entre polimorfismos para diferentes fenótipos da molécula de MHC humano e a periodontite agressiva ou crônica, em caucasianos. Os autores concluíram que alguns polimorfismos como o HLA-A9 e -B15 apresentam uma associação positiva com a periodontite agressiva e que novos estudos devem ser realizados para verificar o valor desses polimorfismos como potenciais marcadores de risco.

Análises genéticos em brasileiros portadores da PAg ainda são escassas, no entanto, um estudo ${ }^{(33)}$ realizado em 2007 avaliou o padrão de segregação da PAg em cinco famílias brasileiras descendentes de africanos e o DNA de quatro indivíduos dessas famílias foi analisado utilizando-se um chip para genotipagem de mais de 10.000 polimorfismos. Os autores concluíram que o modo de herança da doença nessas famílias parece ser autossômico dominante com penetrância muito alta ou completa e que o gene TRAF5, que está envolvido em processos inflamatórios codificando uma proteína da família dos receptores de TNF, é um possível candidato para justificar a susceptibilidade a PAg. 


\section{Tratamento}

O tratamento da doença periodontal agressiva representa um desafio ainda maior, relacionado especialmente a dois aspectos importantes da doença sobre os quais o tratamento convencional não exerce influência: a presença de microrganismos altamente virulentos e a susceptibilidade do hospedeiro. O diferencial nesse tratamento se refere a esforços específicos em afetar a composição e não somente a quantidade da microbiota subgengival. ${ }^{(2)}$ Assim, métodos auxiliares à raspagem e alisamento radicular têm sido estudados objetivando resultados mais previsíveis ao final da terapia periodontal ativa, como a utilização de agentes antimicrobianos locais ou sistêmicos, indicados principalmente no tratamento dos casos de periodontite severa, refratária ou agressiva. ${ }^{(34)}$ Alguns antimicrobianos têm ação de amplo espectro, tipos diferentes podem ser utilizados associados ou sua seleção pode ser direcionada a microrganismos específicos através de testes microbiológicos. ${ }^{(35)}$

O biofilme proporciona um ambiente de proteção aos microrganismos colonizadores contra os mecanismos de defesa do indivíduo e a ação dos antimicrobianos. ${ }^{(35)}$ Seguindo esse raciocínio é que os antimicrobianos devem ser sempre utilizados associados à terapia convencional de raspagem para desorganização do biofilme (Tabela1). 


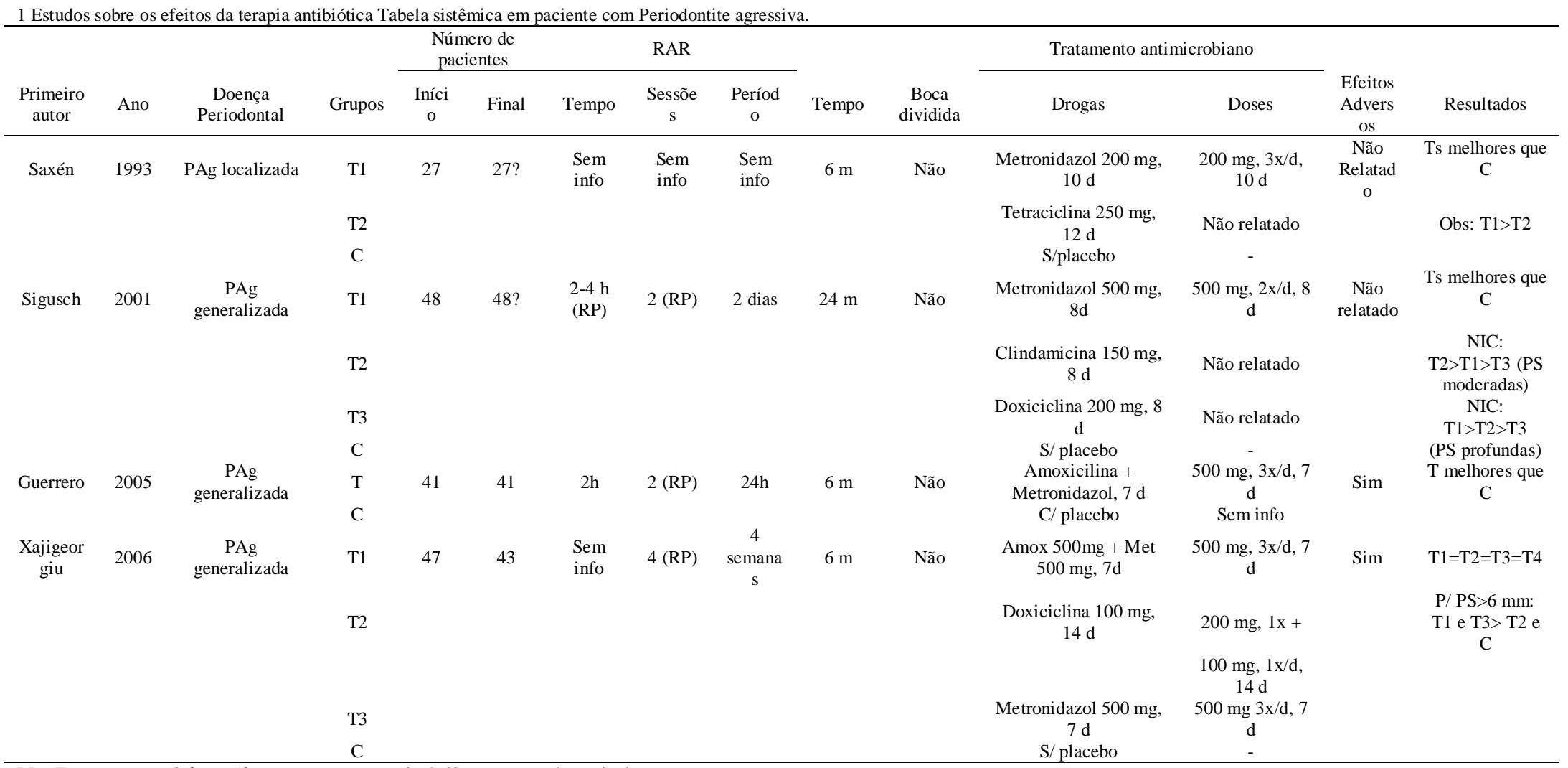

RP: Tratamentp em 2 fases: $1^{\mathrm{a}}$ raspagem supragengival, $2^{\mathrm{a}}$ raspagem subgengival.

?: significa que os números não foram claramente relatados, mas pôde-se concluir através de tabelas de resultados ou assumiu-se nenhuma perda de paciente.

$>$ : significa melhores resultados 
Um estudo clínico controlado ${ }^{(36)}$ realizado com o objetivo de avaliar a utilização da terapia não cirúrgica associada com amoxicilina $500 \mathrm{mg}$ e metronidazol $500 \mathrm{mg}$ (3x ao dia por 7 dias) no tratamento de pacientes com periodontite agressiva generalizada (PAgG), com acompanhamento de 6 meses concluiu que o benefício da amoxicilina + metronidazol, em relação ao tratamento não cirúrgico sozinho, em bolsas profundas foi a redução em média de 1,4 mm na PS e ganho de inserção de 1,0 mm. Em bolsas moderadas os benefícios foram menores em magnitude, com redução da profundidade de sondagem (PS) de 0,4 mm e ganho de inserção de $0,5 \mathrm{~mm}$. O ganho de inserção $\geq 2 \mathrm{~mm}$ ocorreu em $25 \%$ dos sítios em pacientes do grupo teste, comparados com $16 \%$ no grupo placebo. Nesse sentido, uma meta-análise recente $^{(37)}$ tem sugerido que o benefício da terapia adjunta com antimicrobianos pode ser maior em pacientes com PAg, em sítios ativos e em bolsas profundas.

O uso de antimicrobianos locais diversos tem sido bastante reportado na periodontite crônica, mas até o presente momento nenhum estudo foi realizado com a PAg considerando o uso do gel de metronidazol, de micro esferas de minoxicilina e gel de doxiciclina $10 \%$. Existem poucos estudos avaliando a utilização de antimicrobianos locais na PAg com a aplicação de tetraciclina ${ }^{(38,39)}$ e o chip de clorexidina. ${ }^{(40)}$

Um estudo clínico controlado recentemente ${ }^{(40)}$ foi realizado com o objetivo de comparar a eficiência clínica da RAR associada à aplicação subgengival de chips de clorexidina, com a RAR associada ao uso de amoxicilina e metronidazol, no tratamento de pacientes com PAgG. Os autores concluíram que apesar dos benefícios comparáveis entre os grupos 3 meses após o tratamento, ao final de 6 meses após o tratamento a terapia adjunta com o chip de clorexidina se apresentou menos eficiente em relação à redução na PS, ganho de inserção clínica e redução do número de sítios que necessitaram de retratamento, que a associação da amoxicilina com metronidazol. O resultado desse estudo mais uma vez confirma a importância da terapia sistêmica de amoxicilinalmetronidazol adjunta a RAR no tratamento de pacientes com PAg.

De acordo com a Academia Americana de Periodontia (2005), ${ }^{(41)}$ quanto ao papel da irrigação supra e subgengival no tratamento das doenças periodontais, não existe plausibilidade de dados que suportem que um episódio único de irrigação subgengival promova o aumento do impacto imediato ou da duração da eficiência da RAR. Da mesma forma, há informações limitadas para sugerir que múltiplas irrigações em consultas diferentes promovam um benefício substancial na RAR. 
Estudos ainda têm sido realizados avaliando os benefícios clínicos alcançados com a utilização de diferentes medicações moduladoras ${ }^{(42,43)}$ da resposta inflamatória do indivíduo e a terapia fotodinâmica. ${ }^{(44)}$ Uma revisão sistemática se propôs a avaliar o efeito adjunto das terapias moduladoras da resposta do hospedeiro no tratamento de gengivite, periodontite crônica e PAg. A meta-análise concluiu que existem dados insuficientes na literatura sobre pacientes tratados com agentes moduladores, no entanto os anti-inflamatórios não esteróides (AINES) e as drogas bisfosfonadas parecem ter um potencial na terapia periodontal adjunta. Conclui ainda que devido às diferenças na metodologia de tratamento e nas variáveis clinicas dos estudos, é difícil sumarizar a informação e sugerem a realização de estudos multicêntricos. ${ }^{(42)}$

Um trabalho recente foi desenvolvido em 20 pacientes para avaliar os benefícios clínicos, radiográficos e nos níveis de PGE2, em curto prazo (30 dias), do uso adjunto de etoricoxibe $120 \mathrm{mg} /$ dia por 7 dias no tratamento periodontal não cirúrgico da PAg. Os autores concluíram que não houve diferença estatística significante nos parâmetros clínicos observados, apesar de ambos terem apresentado grande melhora. ${ }^{(43)}$

Avaliando os benefícios da terapia fotodinâmica, um estudo ${ }^{(44)}$ conduzido com 10 pacientes com PAg não demonstrou benefícios adicionais em relação à RAR nos parâmetros clínicos periodontais. O mesmo grupo de pesquisadores ${ }^{(45)}$ detectou também níveis similares de TNF$\alpha$ e do receptor ativador do fator nuclear ligante Kappa B nos pacientes tratados com a terapia fotodinâmica e a RAR.

Independentemente da terapia utilizada, a manutenção é essencial para o sucesso longitudinal. ${ }^{(4)}$ A deficiência de estudos sobre a terapia periodontal de suporte (TPS) levou um grupo de pesquisadores a avaliar clínica e microbiologicamente 25 pacientes com PAg tratados com orientação de higiene e RAR. De acordo com as necessidades individuais alguns pacientes foram submetidos à terapia cirúrgica, ou uso de antibiótico ou ainda ambos. Os pacientes incluídos deveriam ter comparecido a no mínimo 10 sessões de TPS em 5 anos, com intervalos de 3 a 6 meses. Os resultados demonstraram que a grande maioria dos sítios submetidos à TPS manteve uma boa estabilidade periodontal, no entanto, um número pequeno de sítios apresentou progressão da doença. Os autores sugeriram alguns fatores associados à progressão da doença como a quantidade de $\mathrm{Pg}$, Tf e carga total bacteriana, número de episódios agudos e de dentes perdidos, fumo e estresse. ${ }^{(4)}$ 


\section{DISCUSSÃO}

A periodontite agressiva não é um assunto exaurido e nem totalmente compreendido na Periodontia. Ao contrário, existem ainda muitas controvérsias e perguntas sem respostas. As discussões se iniciam na terminologia e nos parâmetros determinados pela classificação das doenças periodontais de 1999. ${ }^{(3)}$ Essa classificação se propôs a desfazer a ênfase inapropriada na idade e no índice de progressão da doença e daí a substituição dos termos antigos pela periodontite agressiva. Este, substitue assim os termos periodontite de acometimento precoce, pré-puberal ou juvenil e periodontite de rápida progressão, visto que o profissional dificilmente sabe exatamente quando se iniciou a doença assim como sobre o índice de progressão desta. E por fim, descobriu-se depois que as "periodontites prépuberais", citadas na classificação de 1989, estavam associadas a alterações sistêmicas ${ }^{(3,7)}$ e então, na classificação de 1999, foram agrupadas às periodontites como manifestação de doença sistêmica.

A classificação de 1999 apresenta ainda deficiências que novas classificações tentarão solucionar. Muitas dessas deficiências provêem da falta de conhecimento sobre os fatores etiológicos da doença, se existe um microrganismo ou genes específicos ainda não encontrados responsáveis pela periodontite agressiva, e se de fato ela é uma doença diferente ou apenas a manifestação clínica diferente de uma mesma doença. Os estudos atuais tentam responder ainda a essas questões e a classificação das doenças é de extrema importância científica, para que se possam agrupar nos estudos indivíduos com características mais semelhantes possíveis.

Todas as controvérsias e dificuldades em classificar a doença se tornam perceptíveis nos estudos epidemiológicos. Alguns autores ${ }^{(7)}$ relatam que o pré-requisito fundamental para qualquer estudo epidemiológico é uma definição acurada da doença sob estudo e afirmam que as pesquisas na periodontia ainda não apresentam critérios uniformes.

A apresentação de prevalências tão elevadas da PAg em alguns estudos familiares reafirma a característica de agregação familiar da doença, no entanto, esses valores não podem ser extrapolados a população como um todo, visto que foram realizados a partir de uma amostra selecionada e previamente conhecida como portadora da PAg. ${ }^{(9)}$

Não se tem conhecimento ainda sobre os genes causadores da periodontite agressiva, assim como a forma de herança ainda é discutida, no entanto, estudos familiares vêem apontando a 
genética como um relevante fator de risco para a doença e um importante critério auxiliar no seu diagnóstico. ${ }^{(10,33)}$

A busca por características que diferenciem a periodontite crônica e agressiva e que permitam um diagnóstico precoce da doença tem levado pesquisadores a avaliar e quantificar a presença de células e citocinas no plasma sanguíneo, fluido gengival e periodonto. ${ }^{(24,25)}$ Entretanto, a literatura dispõe de poucos estudos que comparem essas características entre a periodontite crônica e a agressiva. Mesmo quando essas comparações foram feitas, conclusões definitivas não foram alcançadas pela existência de fatores ambientais como raça, idade, diabetes e fumo que também podem alterar a resposta imuno-inflamatória. Além disso, muitas citocinas e mediadores estão envolvidos na resposta do hospedeiro e um mapeamento da maior parte delas talvez seja importante para melhor diferenciação entre periodontite crônica e agressiva.

A classificação de 1999 relata sobre a resposta intensa dos anticorpos aos agentes infecciosos na PAg localizada e uma pobre resposta destes na PAg generalizada, no entanto, ainda não se conhece bem os mecanismos da resposta imune humoral. Por exemplo, não se sabe se os plasmócitos do periodonto produzem anticorpos relevantes ou não totalmente específicos contra os microrganismos do biofilme. ${ }^{(28)}$ Estudo relata uma maior produção da IgG2 na $\mathrm{PAg}^{(24)}$ sem classificar este grupo quanto a portadores da doença generalizada ou localizada.

Características secundárias podem estar associadas a indivíduos portadores da periodontite agressiva, como: anormalidades fagocitárias, fenótipo de macrófagos hiperresponsivos, incluindo índices elevados de PGE2 e interleucina 1-beta (IL-1 $\beta) .{ }^{(1)}$ Dez anos depois, muitos estudos ainda buscam essas confirmações. Existem poucas evidências para os indivíduos saudáveis e com periodontite crônica, e os relatos para a periodontite agressiva sobre as características imunológicas são poucos e contraditórios. ${ }^{(22)}$ Busca-se entender se ocorre de fato um aumento do número de células no periodonto ou apenas um aumento da atividade dessas células, como, por exemplo, os neutrófilos com hiperfunção. ${ }^{(23)}$

Acreditava-se, inicialmente, em uma resposta fraca dos PMN e daí a instalação da PAg. Hoje, acredita-se em um PMN hiper-responsivo na corrente sanguínea ou em um maior acúmulo de PMN nos tecidos periodontais doentes. ${ }^{(23,27)}$ Nos espécimes avaliados os macrófagos se encontravam difusamente espalhados em áreas com e sem grande quantidade de PMN infiltrados, não constatando, portanto a presença de macrófagos hiper-responsivos relatado na classificação dentre as características secundárias. ${ }^{(1)}$ 
Da mesma maneira, pouco se sabe sobre as características genéticas e neste quesito é possível listar uma série de dificuldades, como por exemplo, dificuldade em reunir um número expressivo de pacientes com $\mathrm{PAg}$, o alto custo envolvido nesse tipo de pesquisa, o desenvolvimento relativamente recente da tecnologia para estudo de genes e ainda, segundo meta-análise realizada em 2008, ${ }^{(32)}$ a heterogeneidade dessa doença e os aspectos étnicos da distribuição dos marcadores genéticos.

A distribuição dos principais periodontopatógenos em diferentes populações e etnias não é ainda bem conhecida. A determinação da distribuição global desses microrganismos pode ser importante, já que agentes infecciosos frequentemente apresentam uma limitada distribuição geográfica. ${ }^{(19)}$ Fatores como estratégias de coleta da placa, modo de identificação da bactéria e raça das populações estudadas levam a uma considerável variação na prevalência de certas bactérias entre as populações estudadas.

Segundo uma revisão sistemática ${ }^{(46)}$ sobre os periodontopatógenos da periodontite crônica e agressiva, a simples presença ou ausência de $\mathrm{Aa}, \mathrm{Pg}, \mathrm{Tf}, \mathrm{Cr}$ e $\mathrm{Pi}$ não pode diferenciar pacientes portadores de PAg e crônica. Os autores afirmam ainda que as cepas de Aa altamente leucotóxicas não são unicamente detectadas em indivíduos com PAg, pois uma alta proporção de indivíduos com PAg não demonstrou essa variante e essa observação suporta a possibilidade de que outros fatores possam provocar a doença. Vale ressaltar que o estudo focou apenas na presença ou não dos microrganismos e não na quantidade deles, o que também pode ser um fator importante, afirmam os autores.

A maior parte do conhecimento que se tem relacionado à microbiota periodontal foi obtido a partir de estudos com cultura ou por métodos que requeriam a identificação prévia da bactéria por cultura. Técnicas moleculares recentes, independente de culturas, que fornecem sequências de bactérias periodontais humanas já cultivadas e das ainda não cultivadas, demonstraram uma grande diversidade de espécies bacterianas. ${ }^{(47)}$ Inovações nos métodos de detecção de bactérias podem ser responsáveis pela descoberta de outros periodontopatógenos atuantes na patogênese da PAg.

A PAg pode ser considerada uma doença multifatorial e não há um único tratamento comprovadamente eficiente que possa controlar essa infecção, como vacinas e medicamentos específicos. A escolha do tratamento, no entanto, ainda deve ser guiada pela natureza da microbiota infectante. Obviamente um grande número de pesquisas adicionais é necessário para o desenvolvimento de testes microbiológicos accessíveis aos clínicos para, só então, determinar a melhor terapia para a inibição de cada patógeno. 
Alguns autores demonstram os benefícios adicionais do tratamento periodontal nãocirúrgico associado ao uso de antimicrobianos sistêmicos na $\operatorname{PAg}^{(37)}$ e dentre os antimicrobianos disponíveis a associação da amoxicilina com metronidazol tem ganhado bastante destaque. $\mathrm{O}$ embasamento científico para essa terapia adjunta pode ser confirmado a partir de um recente estudo clínico demonstrando que o amplo espectro de ação conseguido com a associação desses dois medicamentos promoveu benefícios adicionais aos parâmetros clínicos quando comparado ao grupo que recebeu RAR e placebo. ${ }^{(36)}$

No entanto, vale à pena ressaltar que nem todos os pacientes se beneficiam igualmente do uso da amoxicilina+metronidazol e que existem diferenças na susceptibilidade antimicrobiana de importantes periodontopatógenos entre países diferentes, apontando, assim, na direção do uso seletivo dessas potentes terapias antimicrobianas. Tem sido referido ainda que o desafio futuro do diagnóstico e tratamento das PAg envolve uma avaliação individual do risco de cada paciente. ${ }^{(48)}$

Há uma deficiência de estudos que avaliem o efeito do tratamento não-cirúrgico associado à aplicação de antimicrobianos locais, com o uso de substâncias moduladoras da resposta imunológica ${ }^{(49)}$ e da terapia fotodinâmica na PAg, ou mesmo comparando pacientes portadores de periodontite crônica e PAg. Apesar dos possíveis benefícios apontados por alguns estudos ainda não há evidência científica que justifique sua ampla utilização no tratamento de pacientes com PAg.

\section{CONCLUSÕES}

O diagnóstico de periodontite agressiva deve ser realizado com cautela e baseado em dados clínicos, radiográficos e na história da doença.

A periodontite agressiva tem etiologia microbiana com forte influência de fatores imunológicos e genéticos na gravidade da doença.

O tratamento para a PAg com maiores benefícios clínicos, em relação ao tratamento convencional, parece ser a instrumentação periodontal associada à prescrição de antimicrobianos sistêmicos, principalmente a amoxicilina+metronidazol. 


\section{REFERÊNCIAS}

1. Consensus report: aggressive periodontitis. Ann Periodontol. 1999;4(1):53.

2. Tonetti MS, Mombelli A. Periodontite agressiva. In: Lindhe J, Karring T, Lang NP. Tratado de periodontia clínica e implantologia oral. $4^{\mathrm{a}}$ ed. Rio de Janeiro: Guanabara Koogan; 2005. p. 212-33.

3. Armitage GC. Development of a classification system for periodontal disease and conditions. Ann Periodontol. 1999;4:1-6.

4. Kamma JJ, Baehni PC. Five-year maintenance follow-up of early-onset periodontitis patients. J Clin Periodontol. 2003;30:562-72.

5. Papapanou PN. Periodontal diseases: epidemiology. Ann Periodontol. 1996;1(1):1-36.

6. Papapanou PN, Lindhe J. Epidemiologia das doenças periodontais. In: Lindhe J, Karring T, Lang NP. Tratado de periodontia clínica e implantologia oral. $4^{a}$ ed. Rio de Janeiro: Guanabara Koogan; 2005. p. 49-73.

7. Jenkins WMM, Papapanou PN. Epidemiology of periodontal disease in children and adolescents. Periodontology 2000. 2001;26:16-32.

8. Meng H, Xu L, Li Q, Han J, Zhao Y. Determinants of host susceptibility in aggressive periodontitis. Periodontology 2000. 2007;43:133-59.

9. Llorente MA, Griffiths GS. Periodontal status among relatives of aggressive periodontitis patients and reliability of family history report. J Clin Periodontol. 2006;33:121-5.

10. Trevilatto PC, Tramontina VA, Machado MAN, Gonçalves RB, Sallum AW, Line ARP. Clinical, genetic and microbiological findings in a brasilian family with aggressive periodontitis. J Clin Periodontol. 2002;29:233-39.

11. Löe H, Brown LJ. Early onset periodontitis in the United States of America. J Periodontol. 1991;62(10):608-16.

12. Consensus Report. Periodontal disease: prevention. Ann Periodontol. 1996;1(1):250-55.

13. Reichert et al. The interleukin-10 promoter haplotype ATA is a putative risk factor for aggressive periodontitis. J Periodontol Res. 2008;43:40-7.

14. Schacher B, Baron F, Robberg M, Wohlfeil M, Arndt R, Eickholz P. Aggregatibacter actinomycetemcomitans as indicator for aggressive periodontitis by two analyzing strategies. J Clin Periodontol. 2007;34:566-73.

15. Ishikawa I, Kawashima Y, Oda S, Iwata T, Arakawa S. Three case reports of aggressive periodontitis associated with Porphyromonas gingivalis in young patients. J Periodon Res. 2002;37:324-32.

Revista Bahiana de Odontologia, Salvador, dez. 2012; 3(1): 45-63. 
16. Christersson LA, Rosling BG, Dunford RG, Wikesjö UME, Zambon JJ, Genco RJ. Monitoring of subgingival Bacteroides gingivalis and Actinobacillus Actinomycetemcomitans in the management of advanced periodontitis. Adv Dent Res. 1988;2:382-88.

17. van Winkelhoff AJ, Rams TE, Slots J. Systemic antibiotic therapy in periodontics. Periodontology 2000. 1996;10:45-78.

18. Sandros J, Papapanou PN, Nannmark U, Dahlen G. Porphyromonas gingivalis invades human pocket epithelium in vitro. J Periodontol Res. 1994;29(1):62-9.

19. Cortelli JR, Cortelli SC, Jordan S, haraszthy VI, Zambon JJ. Prevalence of periodontal pathogens in Brazilians with aggressive or chronic periodontitis. J Clin Periodontol. 2005;32:860-866.

20. Lopez NJ, Mellado JC, Leighton GX. Ocurrence of Actinobacillus actinomycetemcomitans, Porphyromosnas gingivalis and Prevotella intermedia in juvenile periodontitis. J Clin Periodontol. 1996;23(2):101-105.

21. Kinane DF, Lappin DF. Immune processes in periodontal disease: a review. Ann Periodontol. 2002;7:62-71.

22. Súarez LJ, Ocampo AM, Dueñas RE, Rodriguez A. Relative proportions of t-cell subpopulations and cytokines that mediate and regulate the adaptative immune response in patients with aggressive periodontitis. J Periodontol. 2004;75:1209-1215.

23. Figueredo CMS, Fisher RG, Gustafsson A. Aberrant neutrophil reactions in periodontitis. J Periodontol. 2005;76:951-955.

24. Graswinckel JEM, van der Velden U, van winkelhoff AJ, Hoek FJ, Loos BG. Plasma antibody levels in periodontitis patients and controls. J Clin Periodontol. 2004;31:562-568.

25. Havemose-Pousen A, Sorensen LK, Stoltze K, Bendtzen K, Holmstrup P. Cytokine profiles in peripheral blood and whole blood cultures associated with aggressive periodontitis, juvenile idiopathic arthritis, and rheumatoid arthritis. J Periodontol. 2005;76:2276-2285.

26. Sorensen LK, Havemose-Pousen A, Bendtzen K, Holmstrup P. Aggressive periodontitis and chronic arthritis: blood mononuclear cell gene expression and plasma protein levels of cytokines and cytokine inhibitors. J Periodontol. 2009;80:282-289.

27. Liu RK, Cao CF, Meng HX, Gao Y. Polymorphonuclear neutrophils and their mediators in gingival tissues from generalized aggressive periodontitis. J Periodontol. 2001;72:15451553.

28. Kinane DF, Berlundh T, Lindhe. Interações entre parasitas e hospedeiros na doença periodontal. In: Lindhe J, Karring T, Lang NP. Tratado de periodontia clínica e implantologia oral. $4^{\mathrm{a}}$ ed. Rio de Janeiro: Guanabara Koogan; 2005. p. 148-71 
29. Kinane DF, Lapping DF, Koulouri O, Buckley A. Humoral immune responses inperiodontal disease may have mucosal and systemic immune features. Clin Exp immunol. 1999; 115(3):534-41.

30. Lappin DF, McGregor AMP, Kinane DF. The systemic response is more prominent than the mucosal immune response in the pathogenesis of periodontal disease. J Clin Periodontol. 2003;30(9):778-86.

31. Nikolopoulos GK, Hamodrakas SJ, Bagos PG. Cytokine gene polymorphisms in periodontal disease: a meta-analysis of 53 studies including 4178 cases and 4590 controls. J Clin Periodontol. 2008;35:754-67.

32. Stein JM, Machulla HKG, Smeets R, Lampert F, Reichert S. Human leucocyte antigen polymorphism in chronic and aggressive periodontitis among Caucasians: a meta-analysis. J Clin Periodontol. 2008;35:183-92.

33. Carvalho FM, Vieira AR, Tinoco EMB. Genética da periodontite agressiva em brasileiros: resultados preliminares em famílias de ascendência africana. $\mathrm{R}$ Periodontia. 2007;17(3): 35-40.

34. Haffajee AD, Socransky SS, Lindhe J. O Efeito da terapia na microbiota da região dentogengival. In: Lindhe J, Karring T, Lang NP. Tratado de periodontia clínica e implantologia oral. $4^{\mathrm{a}}$ ed. Rio de Janeiro: Guanabara Koogan; 2005. p.542-553.

35. Slots J, Jorgensen MG. Effective, safe, practical and affordable periodontal therapy: where are we going, and are we there yet? Periodontology 2000. 2002;28:298-312.

36. Guerrero et al. Adjuntive benefits of systemic amoxicillin and metronidazole in nonsurgical treatment of generalized aggressive periodontitis: a randomized placebo-controlled clinical trial. J Clin Periodontol. 2005;32:1096-1107.

37. Herrera D, Sanz M, Jepsen S, Needleman I, Roldán S. A systematic review on the effect of systemic antimicrobials as an adjunct to scaling and root planning in periodontitis patients. J Clin Periodontol. 2002;29:136-59.

38. Purucker P, Mertes H, Goodson JM, Bernimoulin JP. Local versus systemic adjunctive antibiotic therapy in 28 patients with generalized aggressive periodontitis. J Periodontol. 2001 Sup;72(9):1241-5.

39. Mombelli A, Schmid B, Rutar A, Lang NP. Local antibiotic therapy guided by microbiological diagnosis. Treatment of Porphyromonas gingivalis and Actinobacillus actinomycetemcomitans persisting after mechanical therapy. J Clin Period. 2002;29(8):743-9.

40. Kaner D, Bernimoulin J-P, Hopfenmüller W, Kleber B-M, Friedmann A. Controlleddelivery chlorhexidine chip versus amoxicilin/metronidazole as adjunctive antimicrobial therapy for generalized aggressive periodontitis: a randomized controlled clinical trial. J Clin Periodontol. 2007;34:880-891. 
41. Committee on Research, Science, and Therapy Committee of the American Academy of Periodontology. Academy Report. Position Paper. The role of supra- and subgingival irrigation in the treatment of periodontal diseases. J Periodontol. 2005;76:2015-2027.

42. Reddy MS, Greus NC, Gunsolley JC. Periodontal host modulation with antiproteinases, anti-inflammatory, and bone-sparing agents. A systematic review. Ann Periodontol. 2003;74(1):12-37.

43. Azoubel et al. Adjunctive benefits of systemic etoricoxib in non-surgical treatment of aggressive periodontitis: short-term evaluation. J Periodontol. 2008;79:1719-1725.

44. Oliveira RR, Schwartz-Filho HO, Novaes Jr AB, Taba Jr M. Antimicrobial photodynamic therapy in the non-surgical treatment of aggressive periodontitis: a preliminary randomized controlled clinical study. J Periodontol. 2007;78:965-973.

45. Oliveira et al. Antimicrobial photodynamic therapy in the non-surgical treatment of aggressive periodontitis: cytokine profile in gingival crevicular fluid, preliminary results. $\mathbf{J}$ Periodontol. 2009;80:98-105.

46. Mombelli A, Casagni F, Madianos PN. Can presence or absence of periodontal pathogens distinguish between subjects with chronic and aggressive periodontitis? A systematic review. J Clin Periodontol. 2002;29(suppl. 3):10-21.

47. Papapanou PN. Population studies of microbial ecology in periodontal health and disease. Ann Periodontol. 2002;7:54-61.

48. Van Winkelholff AJ. Antibiotics in periodontitis: are we getting somewhere? J Clin Periodontol. 2005;32(10):1094-5.

49. Committee on Research, Science, and Therapy Committee of the American Academy of Periodontology. Academy Report. Information Paper. Modulation of the host response in periodontal therapy. J Periodontol. 2002;73:460-470. 